\title{
Primary Mental Health Care Part 1: A Critical Review of the Irish System
}

\author{
Smith L, *Aherne D, O’Shea J \\ University of Limerick, Castletroy, Limerick, Ireland
}

\begin{abstract}
Primary mental health care is an evolving system, in need of regular revision and requiring innovative and creative adjustments in order to provide the public with an easily accessible and appropriate level and type of service, based on best practice and evidence. This paper is the first in a series of three exploring primary mental health care. The Irish model of care, 'Counselling in Primary Care', is presented as well as a number of short-comings associated with that model. The short-comings include eligibility criteria governing access, limitations of service as well as waiting lists; and the medicalization of service delivery.
\end{abstract}

Keywords: Mental health, Counselling, Primary care

\section{Introduction}

Acknowledging the need to update Irish mental health policy and service delivery in 2003, the Department of Health and Children (DoHC) commissioned a national policy framework to guide the modernization of mental health services in Ireland. The framework, detailed in a policy document referred to as "A Vision for Change" $(\mathrm{AVFC})^{1}$ set forth guidance on the implementation of the new mental health system to be launched and rolled out over the next decade.

Central to the need for change in service delivery was the lack of standardized care for people with mental health concerns in Ireland. Emphasis within AVFC was placed on early intervention and coordinated services within the Health Service Executive (HSE). A core element of the policy was the collaboration (or shared-care) between the general practitioner (GP) within primary care and mental health teams within secondary mental health care. ${ }^{2}$ One role of the GP, therefore, was to act as 'gatekeeper' to mental health professionals and specialist services where the GP would '... detect and diagnose mental health difficulties and either treat the individual or refer him/her to specialist services.3
Despite the early widespread support for AVFC, analysis of progress is disappointing. ${ }^{4,5}$ The briefing paper on PMHC in Ireland states that of all recommendations made by AVFC, those put forward for primary care have been the least implemented of all. ${ }^{3}$ The second interim report for the future of mental health care in Ireland ${ }^{6}$ noted the continued lack of cohesive actions between primary care and mental health services; the limited referral pathways and clarity for service users in primary care to secondary, tertiary, or community supports; and the over-reliance on psychopharmacology and paucity of investment in the talk therapies.

'Sharing the Vision' (StV), ${ }^{7}$ the government's follow up document to AVFC, has just been published, as of June 2020. The document itself has focused on what service users want and need from their mental health service. This level of service user involvement and consultation is to be commended, however the document focuses on broad generalizations as regards changes to services, rather than an implementable plan as to how these changes can be made. Regrettably, the document continues to focus on G.P.s together with $\mathrm{A} \& \mathrm{E}$ admissions as the predominant access route to men-

\begin{tabular}{|l|l|}
\hline \hline Quick Response Code: & $\begin{array}{l}\text { *Corresponding author: Lucy Smith, Clinical Psychology, Dip. Humanistic and Integrative } \\
\text { Psychotherapy). Clinical Psychologist, Psychotherapist, and Head of Counselling, University of } \\
\text { Limerick, Castletroy, Limerick, Ireland } \\
\text { Received: } 11 \text { May, } 2021 \quad \text { Published: } 18 \text { June, } 2021 \\
\text { Citation: Smith L, Aherne D, O’Shea J. Primary Mental Health Care Part 1: A Critical Review of } \\
\text { the Irish System. J Psych Sci Res. 2021;1(2):1-5. DOI: 10.53902/JPSSR.2021.01.000508 }\end{array}$ \\
\hline
\end{tabular}


tal health services in Ireland, which perpetuates the same issues of accessibility. While the follow up to AVFC has been anticipated and required for some time, the timing of the publication may prove critical. StV has been published just as a new government is about to be formed, creating many questions as to what this means for recommendations set out in the document. Further, the document was written pre Covid 19, meaning Ireland's financial environment has completely changed, and mental health service delivery has been impacted and is likely to face challenges of delivery for some time to come.

This paper describes the current model of primary mental health care for adults in Ireland and discusses the limitations of that model. The aim of this article is to demonstrate, through these limitations, the need for an overhaul (rather than a continuation) of the current mental health system in Ireland.

\section{The Current Model in Ireland: Counselling in Primary Care (CIPC)}

"This basic level of care acts as a filter between the general population and specialized health care" 8

Guided by the recommendations of AVFC, a PMHC model was selected and launched by the HSE in July 2013. This model, referred to as 'Counseling in Primary Care' (CIPC), aims to provide counseling for those with mild to moderate mental health concerns who present to their primary care setting. Counseling itself takes place in a variety of different settings nationwide, ranging from Primary Care Centers, GP surgeries, National Counseling Services (NCS) (originally developed in response to those who experienced clerical abuse as children), and Community/Voluntary Sector Centres. ${ }^{9}$ The directors of the NCS are charged with responsibility for rolling out the CIPC model and with overseeing local CIPC co-coordinators tasked with actively delivering services. The concepts of AVFC are central to the CIPC model; i.e., a single point of access for mental health care; referral to secondary mental health care where necessary; integration of service within the community; and co-ordination of service delivery. ${ }^{1}$

CIPC incorporates a set of criteria governing accessibility. Access to this model demands service users to be over the age of 18, to hold a General Medical Services (GMS) card, and to be referred through their GP or through members of the Primary Care Team (PCT) with the knowledge of their GP. ${ }^{9}$ Within the first two years of its launch, 16,000 referrals were made to CIPC by GPs. ${ }^{5}$ The report from Phase 1 of the CIPC National Evaluation Study reveals that 19,000 referrals were made during 2017 with counseling provided at more than 180 locations nationwide by 148 counsellors. ${ }^{9}$ On average, this amounts to 105 referrals per location over the year 2017. Since the launch of CIPC in May 2013, the number of referrals has grown to an average of 1,500 each month in 2017. It is clear that demand for counseling at primary care is on the increase.

CIPC outcome data is also promising. The 2018 Evaluation of Phase 1 reveals that therapists provide a range of treatment approaches, providing that needed by each individual client when they present for help (e.g., integrative, cognitive-behavioral, or person-centered approaches). Therapeutic factors such as client centered work are in operation, indicating that therapists have the skill and flexibility to work with the needs of their client rather than provide a one size fits all model of therapy. In addition, the outcome data reveals a reduction of impairment and distress at therapy completion. Evaluation of well-being at follow-up periods of 6 and 12 months is currently underway although this data is yet to be published.

\section{Limitations of CIPC}

Neither the need for a primary care mental health service nor the capacities to provide good therapeutic care at that level are in doubt. However, it is the model itself that appears to be lacking.

A summary assessment report of progress on the implementation of the mental health policies identified in AVFC was published in 2015 by the Mental Health Reform. ${ }^{5}$ This report systematically considered each of the core areas of mental health service provision, including primary care. A butterfly symbol, widely used throughout AVFC policy document, is employed once again throughout the progress report. A blank white butterfly depicts areas of little to no change whilst a solid pink butterfly depicts full implementation of recommendations with respect to the mental health topic in question. Notably, it is a blank white butterfly that represents the progress pertaining to implementation of policy with respect to PMHC. Some of the identified shortcomings, and others, are expanded upon below. These include: eligibility criteria; limitations of service and waiting lists; as well as the medicalization of service delivery.

\section{Eligibility criteria}

The CIPC service is available only to those over the age of 18 and those with a GMS card. These specifications limit access to PMHC clearly ruling out those younger than 18 and those whose income exceeds the cut off for a medical card. Those on a low income but without a medical card are less likely to visit their GP for help due to the cost of the consultation ${ }^{10}$ and those that do visit without a medical card may well be referred to the community mental health services, at secondary care level. This, in turn, drains resources and input for those with more complex mental health needs. As such, the current primary mental health care service in Ireland is inequitable and impedes unnecessarily on secondary level mental health care.

\section{Limitations of service and waiting lists}

Whilst primary care counseling is necessary and welcome, CIPC provides a limit of eight sessions to those limited few who have access to the service. This is problematic at a primary care service which relies on GP referral. The research evidence clearly identifies a relationship between severity and chronicity of symptoms and delay in presentation to GP. ${ }^{11}$ Thus, the greater the psychological difficulty, the longer people tend to leave it before seeking help. Mirroring this finding, almost $90 \%$ of the participants within the evaluation study presented with levels of distress related to symptoms ongoing for longer than 12 months. ${ }^{9}$ The GP mediated CIPC service is under pressure, therefore, to work with those who have longer lasting and a greater severity of mental health problems rather than 
intervening early in the development of mental health problems. A limit of eight sessions, whilst effective for those with lower-level problems, is unlikely to be sufficient for long-term change. Given the ever-increasing number of people seeking mental health care between 2013-2018,5,9 limiting session number is a realistic manner of providing some kind of service delivery to those in need of it. However, this is not to be confused with the provision of adequate therapeutic input.

A further problem identified by the Mental Health Reform ${ }^{5}$ and $\mathrm{HSE}^{9}$ is the length of waiting lists. A primary mental health care service should, by nature, be an immediate and early intervention service for those experiencing psychological problems. However, the report by the Reform in 2015 revealed 'lengthy' waiting lists for some people, and a wait of more than six months for 81 people referred to the service. Meanwhile, the first report on the National Evaluation Study revealed $76-80 \%$ of service users waiting $0-4$ months and $20-24 \%$ waiting between 4-6 months. ${ }^{9}$

One of the central elements within AVFC was that service users become active participants in their own care.1 Service users are increasingly looking for psychological help and talk therapies over pharmacotherapy.,12-14 Were their requests being recognized and responded to then it might be considered that the vision of "active participation" is being met. However, this is not the case, given the over-reliance on psychopharmacology, ${ }^{6}$ the long waiting lists at CIPC $^{5,9}$ and the reserved eligibility of CIPC to all patients. Those who do receive a service are faced with the eight session limit, regardless of their need. This conflicts with a core element of AVFC; that of placing the needs of the service user central to service delivery. ${ }^{1}$

\section{The medicalization of service delivery}

It is of no surprise that the first evaluation report of CIPC has identified an increase in referrals for talk therapies over the past five years. ${ }^{9}$ This concurs with trends from service user preference studies which specify twice as many people prefer psychological treatment to pharmacotherapy. ${ }^{12-14}$ It is well established that medication for anxiety and depression is often prescribed against treatment guidelines, often too soon and/or for too long. ${ }^{15-18}$ A systematic review by Aherne, Aherne, Fitzgerald, et al. ${ }^{19}$ found no evidence to support the NICE recommendation for the use of anti-depressant medication for people with moderate depression. Furthermore, Cipriani, Furukawa, Salanti, et al. ${ }^{20}$ found that for those with severe depression, medication was little better than placebo. The research evidence is also compelling regarding the effectiveness of the psychological approaches, ${ }^{21-24}$ yet a mismatch exists between current practice and the contradictory empirical evidence for talk therapies.

Although it is accepted as best practice that psychologically-based interventions are offered as the first line treatment prior to medication, ${ }^{25}$ there is ubiquitous agreement regarding the over-reliance on medication by GPs. ${ }^{1,2,6}$ With 10 million euro spent on talk therapies and 400 million spent on psychotropic medication a year in Ireland, ${ }^{6}$ the problem is one of financial investment. GPs themselves acknowledge the need for primary care psychological services ${ }^{26}$ and have been calling for rapid non-pharmacological in- terventions for those with mild-moderate depression. ${ }^{27}$ The Irish College of General Practitioners (the ICGP) continue to acknowledge this issue today, unequivocally stating there to be excessive spending on hospital-based care, specialist care, administration, and pharmacological therapies to the dire neglect of primary care and talk therapies. ${ }^{6}$

This reliance on psychopharmacology over psychotherapy is not unique to Ireland. In the United States ${ }^{28,29}$ and in Australia ${ }^{30}$ increasing numbers of people with mental health problems have been presenting to their medical practitioner over the past number of decades. However, despite increasing demand ${ }^{13,9}$ and strong evidence base for psychotherapy over pharmacological interventions, ${ }^{24}$ the use of pharmacotherapy is increasing whilst psychotherapy is on the decrease. ${ }^{28,29}$ It seems plausible that this is a response to the intentional focus on the neurobiological cause, medicalization, and diagnostic approach to mental illness ${ }^{31-35}$ as well as direct and indirect influences by the psychopharmaceutical companies. ${ }^{36}$ The over-reliance on medication found among Irish GPs is not, therefore, specific to Ireland but a reflection of a global push by pharmaceutical companies for the use of medication in treating mental health. This push is perpetuated by medical practitioners who rely on such interventions when there is a paucity of resources for talk therapies and long waiting lists to access those resources that do exist. $^{5}$

The Shared Care Approach guidance paper between primary and specialist mental health services acts as the 'road map' to collaborative working between PMHC and specialist mental health services. $^{2}$ These guidelines acknowledge the need for sufficient numbers of 'appropriately trained' professionals to work effectively with patients presenting with mental health difficulties. The professionals holding an appropriate level of expertise and skill in dealing with mental health include psychologists, psychotherapists, and counselors. Less than $50 \%$ of GPs receive even rudimentary training in dealing with psychological issues of their patients, ${ }^{37}$ indicating that, as a group of clinicians, GPs are not appropriately trained to identify, diagnose, and effectively treat patients with mental health presentations. This over reliance on GP as gatekeeper to mental health care services is a drain on their resources, limiting both the amount of patients they can see and the amount of time spent with each patient. Progress assessment of AVFC policy clearly acknowledges that GPs lack requisite training in mental health and that this '...is a significant obstacle to effective use of primary care' ( $\mathrm{p}$. 20). ${ }^{5}$ Therefore, despite acknowledging that psychologists and psychotherapists are the ideal professionals to deal with mental health and despite acknowledging the lack of GP training, there is ongoing concomitant expectation that GPs play the role of gatekeeper in mental health care. Not only, therefore, are patients at risk of being mismanaged regarding their mental health, but they are also likely to be over, under, and mis-diagnosed. Recent research investigating factors culminating in the worst-case scenario of mental health, i.e., suicide, identified a number of factors central to poor outcomes for patients with mental health difficulties. ${ }^{38}$ These factors included: lack of GP training, the brevity of the GP consultation, and the disjointed nature of the wider system. The conclusion of this research 
is clear, GPs are not equipped to hold the role of gatekeeper in the treatment of mental health.

Competencies and training aside, it is also plausible that some GPs may lack the required interest or desire to deal with mental health problems. The research by Leavey, et al. ${ }^{38}$ reveals GPs to be fuelled by scepticism and overwhelm regarding patients with such presentations. This research also identifies a perception by GPs that they are dictated to by some patients looking for medication, sick-certs, and disability allowance on the basis of mental illness. Working limitations within the GP system is also problematic. The 'ten-minute rule' for a GP consultation is constricting for both GP and patient. ${ }^{38}$ For those patients presenting with genuine mental health problems, mental health stigma precludes some from effectively communicating their mental health status within the ten-minute period, with many only doing so throughout the last minute of the consultation. Limited consultation time precludes the possibility of meaningful dialogue about mental health between patient and GP, even among those GPs who consider 'counseling' as part of their role. ${ }^{38}$

Despite all of this, it remains both in practice and in principle, that the medically trained GP is designated 'gatekeeper' to mental health support and holds responsibility for the referral of mental health presentations to primary mental health care. ${ }^{1,2}$ Notable recommendations within the document suggest that primary care and mental health services should be co-located where possible, that ongoing meetings take place between the mental health services and the GP, and that a greater emphasis in mental health takes place within the training of the GP. Despite the shared-care recognition for appropriately trained professionals within the primary care mental health system, the document and the recommendations proposed simply perpetuate the connection to medically based primary care with the GP at the centre of the model.

More significantly perhaps is the fact that the current medical model of service delivery in primary care is lacking an evidence base. No known research demonstrates the effectiveness of GP intervention with people who have mental health problems. The author's stress that this point is not to be interpreted as criticism of GP's themselves, nor their highly trained capacity to deliver medical care to their physically unwell patients. Instead, we are highlighting that the placing of mental health care within the medical model is not the ideal modality of intervention for mental health, much less at a primary care level. This current system, mediated by GPs, serves to exhaust the very limited existing resources on offer.

\section{Conclusion}

This paper summarizes the current model of PMHC within the Irish system and its limitations. In line with this paradigm shift, the authors propose that whilst GPs have traditionally held the role of mental health gatekeeper within the community, they are not the professionals most suited to the role. The authors suggest that the GP mediated CIPC model requires genuine review and revision. In light of the above rationale, it is argued here that primary mental health care first and foremost needs to be considered beyond the scope of a medical framework. Such models already exist and are explored in the two subsequent papers which follow in this series.

\section{Acknowledgments}

None.

\section{Funding}

None.

\section{Conflicts of Interest}

Author declares that there is no conflict of interest.

\section{References}

1. Irish Department of Health \& Children. A vision for change: report of the expert group on mental health policy. Dublin: Stationary Office; 2006.

2. Health Service Executive. Health Service Executive Primary Care and Mental Health Group. Advancing the shared care approach between primary care and specialist mental health services: a guidance paper. Naas: Office of the Assistant National Director Mental Health; 2012.

3. Mental Health Reform. Mental Health in primary care in Ireland: A briefing paper. Dublin: Mental Health Reform; 2013.

4. Keogh K. From vision to action: An analysis of the implementation of A Vision for Change. Dublin: Mental Health Commission; 2009.

5. Mental Health Reform. A vision for change: nine years on: A coalition analysis of progress. Dublin: Mental Health Reform; 2015.

6. Oireachtas. Second interim report: recommended actions arising from progress made to date. Dublin: Joint committee on the future of mental health care; 2018.

7. Irish Department of Health. Sharing the Vision: A Mental Health Policy for Everyone. Dublin: Stationary Office; 2020.

8. World Health Organization (WHO). The world health report 2001: Mental health -New understanding, new hope. Switzerland: WHO; 2001.

9. Health Service Executive. Counselling in Primary Care Services: National Evaluation Study. Report of Phase 1. Dublin: Stationary Office; 2018.

10. Nolan A. Nolan B. Ireland's healthcare system: Some issues and challenges. Dublin: ESRI. 2004.

11. Bebbington PE, Meltzer $\mathrm{H}$, Brugha TS, et al. Unequal access and unmet need: neurotic disorders and the use of primary care services. Psychol Med. 2000;30(6):1359-1367.

12. Brettle A, Hill A, Jenkins P. Counselling in primary care: a systematic review of the evidence. Counselling and Psychotherapy Research. 2008;8(4):207-214.

13. Clark D, Turpin G. Improving opportunities. The Psychologist. 2008;21(8):700-701.

14. Kwan BM, Dimidjian S, Rizvi SL. Treatment preference, engagement, and clinical improvement in pharmacotherapy versus psychotherapy for depression. Behaviour research and therapy. 2010;48(8):799-804.

15. Meijer WE, Heerdink ER, Leufkens HG, et al. Incidence and determinants of long-term use of antidepressants. European journal of clinical pharmacology. 2004;60(1):57-61.

16. Johnson CF, Macdonald HJ, Atkinson P, et al. Reviewing long-term antidepressants can reduce drug burden: a prospective observational cohort study. British Journal of General Practice. 2012;62(604):e773779.

17. Petty DR, House A, Knapp P, et al. Prevalence, duration and indications for prescribing of antidepressants in primary care. Age and ageing. 2006;35(5):523-256. 
18. Mojtabai R, Olfson M. National trends in long-term use of antidepressant medications: results from the US National Health and Nutrition Examination Survey. The Journal of clinical psychiatry. 2014;75(2):169177.

19. Aherne D, Fitzgerald A, Aherne C, et al. Evidence for the treatment of moderate depression: a systematic review. Irish journal of psychological medicine. 201;34(3):197-204.

20. Cipriani A, Furukawa TA, Salanti G, et al. Comparative efficacy and acceptability of 21 antidepressant drugs for the acute treatment of adults with major depressive disorder: a systematic review and network meta-analysis. Focus. 2018;16(4):420-429.

21. Wampold BE. The great psychotherapy debate: Models, methods, and findings. Lawrence Erlbaum Associates Publishers; 2001.

22. Carr A. The effectiveness of psychotherapy: A review of research prepared for the Irish Council for Psychotherapy.Dublin: ICP; 2007.

23. Brent D, Emslie G, Clarke G, et al. Switching to another SSRI or to venlafaxine with or without cognitive behavioral therapy for adolescents with SSRI-resistant depression: the TORDIA randomized controlled trial. JAMA. 2008;299(8):901-913.

24. Shedler J. The efficacy of psychodynamic psychotherapy. American psychologist. 2010;65(2):98.

25. Health Service Executive. Best Practice Guidance for Mental Health Services. Dublin: Stationary Office; 2017.

26. Byrne M. GPs want access to psychology services. Forum. 2007;24(9):5759.

27. Ni Shiothcháin A, Byrne M. What do GPs want from mental health services? Irish Psychiatrist. 2009;10(1):42-44.

28. Olfson M, Marcus SC, Druss B, et al. National trends in the outpatient treatment of depression. JAMA. 2002;287(2):203-209.
29. Marcus SC, Olfson M. National trends in the treatment for depression from 1998 to 2007. Archives of general psychiatry. 2010;67(12):12651273.

30. Reavley NJ, Yap MB, Wright A, et al. Actions taken by young people to deal with mental disorders: findings from an Australian national survey of youth. Early Intervention in Psychiatry. 2011;5(4):335-342.

31. American Psychiatric Association. Diagnostic and Statistical Manual of Mental Disorders. $5^{\text {th }}$ ed. Washington DC: Author $\left(1^{\text {st }}\right.$ ed, $1952 ; 2^{\text {nd }}$ ed, $1968 ; 3^{\text {rd }}$ ed, $1980 ; 3^{\text {rd }}$ ed rev. $1987 ; 4^{\text {th }}$ ed, $1994 ; 4^{\text {th }}$ ed, text revision, 2000). 2013.

32. Corrigan PW, Watson AC. At issue: Stop the stigma: Call mental illness a brain disease. Schizophrenia Bulletin. 2004;30(3):477-479.

33. Pescosolido BA, Martin JK, Long JS, et al. "A disease like any other"? A decade of change in public reactions to schizophrenia, depression, and alcohol dependence. American Journal of Psychiatry. 2010;167(11):13211330 .

34. Mackenzie CS, Erickson J, Deane FP, et al. Changes in attitudes toward seeking mental health services: A 40-year cross-temporal meta-analysis. Clinical Psychology Review. 2014;34(2):99-106.

35. Bullmore E. The inflamed mind: A radical new approach to depression. London: Short books; 2018.

36. Watson, J. Drop The Disorder!:Challenging the culture of psychiatric diagnosis. Wyastone Leys, Monmouth, UK: PCCS Books; 2019.

37. Healy D, Naqvi S, Meagher D, et al. Primary care support for youth mental health: a preliminary evidence base for Ireland's Mid-West. Irish journal of medical science. 2013;182(2):237-243.

38. Leavey G, Mallon S, Rondon-Sulbaran J, et al. The failure of suicide prevention in primary care: family and GP perspectives - a qualitative study. BMC Psychiatry. 2017;17:369-379. 